\title{
Aureli Lojo
}

\section{Young Chinese in Europe: \\ Travel behavior and new trends based on evidence from Spain}

\begin{abstract}
Chinese tourism in Europe has tripled over the last decade to reach 6 million tourists in 2018. Understanding tourist behavior allows for improvement of the tourist experience and better management of destinations. To these ends, this study analyzes (1) the motivations, expectations and satisfaction of Chinese tourists and (2) defines the main differences between young Chinese (18-29 years old) and more mature Chinese tourists. Data is extracted from 360 survey questionnaires that were administered to tourists after their trips to Europe. Destination Spain, in Western Europe, is selected as the case study. Mean analysis, one-factor ANOVA and multivariate analysis of variance (MANOVA) have been conducted. The results show that more mature travelers have significant differences in the travel arrangements, motivations, expectations and evaluations of their trips than do younger travelers. Younger tourists chose independent trips, while the more mature ones chose either full group packages or independent trips. The younger have a wider range of motivations and preferences for activities at their destinations. New trends in Chinese tourists visiting Europe are discussed and implications for the destination are explored.
\end{abstract}

Key words: Chinese tourism; tourism behavior; young tourist; Spain; Europe

\section{Introduction}

Since 2012, China is the number one source country for international tourists, and the quantity of outbound Chinese tourists continues to rise. In 2018, 150 million tourists traveled outside the borders of mainland China, which constitutes an increase of $11.1 \%$ over the previous year (Xinhua, 2019). In addition, about $90 \%$ of the Chinese population still does not have a passport, so it is assumed that the number of tourists will continue to increase in the near future (Travel China Guide, 2018). Moreover, Chinese tourists stand out because they are the top spenders outside of their country. In 2018, their spending reached 261 billion dollars (Xinhua, 2019). For these reasons, many international tourism destinations try to attract these tourists and position themselves in the Chinese market. Previous tourism research shows that for destinations to access new international markets it is important to develop collective initiatives, as well as define and understand the target markets (Rodriguez-Giron, 2018).

Chinese tourism in Europe has tripled in the last 10 years, reaching 25 million overnight stays in hotels in 2016 (Eurostat, 2018). The number of tourists who traveled to Europe reached 6 million in 2018 (People's Daily, 2019). 2018 was the "EU-China Tourism Year", which was organized by the European Commission in collaboration with the European Travel Commission (ETC). This was an initiative designed to help EU authorities over the tourism business and other stakeholders participating in Chinese tourism. As a result, during January 2018 to December 2018 there was a 5\% increase in Chinese arrivals in the European Union destinations (ETC, 2019). According to the ETC, the initiative has been successful and benefits have also been seen in 2019.

Aureli Lojo, PhD, Department of Geography, TUDISTAR Tourism Research Group, Universitat Autònoma de Barcelona, Barcelona, Spain; e-mail: aureli.lojo@gmail.com 
In a recent study, the Chinese Tourism Academy (CTA, 2019) found that the UK, Italy, France, Switzerland, Spain, and Greece were the most popular destinations for private Chinese tours to Europe. However, the countries with the biggest yearly growth rate of Chinese arrivals in the first half of 2019 were located in East Europe: Croatia (+540\%), Latvia (+523\%), Slovenia (+497\%), Bulgaria (+459\%), and Estonia (+321\%).

In recent years, numerous studies have been devoted to understanding Chinese tourists in Europe (e.g. Andreu, Claver, \& Quer, 2014; Kapiki, Fu, \& Mou, 2015; Skivalou \& Filippidi, 2017; Agacevic $\& \mathrm{Xu}, 2020)$. The most recent publications agree that the consumer behavior and profile of tourists are changing. The evolution and maturation of the Chinese market implies diversification and the emergence of new consumers. Young Chinese tourists have more experience in international travel, and they are beginning to embrace different consumption patterns. For example, the earlier tourists were primarily motivated by their appreciation of modernity; Now they already benefit from modernity in their daily lives in China and they thus value what they do not have in their own country, such as clean and pollution-free natural landscapes (Jin \& Wang, 2016).

According to Jørgensen, Law, and King (2018), studies on Chinese tourism tend to be repetitive and offer a stereotypical view of tourists. Lojo and $\mathrm{Li}$ (2018) indicate that most previous studies fail to show the differences between different tourism segments. In addition, reviews of the academic literature on Chinese tourism (Jin \& Wang, 2016; Jørgensen, Law, \& King, 2016; Lojo, 2016b; Lojo, Li, \& Cànoves, 2019) indicate that Europe and European countries are destinations in which Chinese tourism has not been sufficiently studied.

Framed in the context of Spain and with the objective of providing knowledge for improving the tourist's experience as well as destination management, this paper has the following research aims: (1) to analyze the motivations, expectations and satisfaction of Chinese tourists in Europe; (2) identify the main differences between younger and more mature tourists; (3) and to define the new trends in Chinese tourism behavior in Europe. To achieve these aims, this article presents a case study with a set of collected data. In addition, the Discussion section offer a synthesis of current and future perspectives in Chinese tourist behavior in Europe.

\section{Study context: Spain and young Chinese tourists}

The tourist experience is a complex field of study because the tourist's behavior depends on multiple elements, decisions and sub-decisions. In addition, tourist behavior is also influenced by the psychological and cultural values of tourists and their communities of origin (Hsu \& Huang, 2016). Behavior paradigms in tourism are often associated with the analysis of very different variables (Smallman \& Moore, 2010), such as motivations (e.g. Maumbe \& Arbogast, 2015), satisfaction or loyalty (Anil, 2012). In this article to understand the behavior and new trends in Chinese tourism, we analyze the variables of motivations, expectations and evaluations of tourist travel in a defined specific context.

\subsection{Chinese tourism in Spain}

The study context of this article is Spain. The number of Chinese tourists in Spain has increased almost five times in the last 7 years, from 178 thousand tourists in 2012 to 646 thousand in $2018(+25.4 \%$ over the previous year) (Turespaña, 2019). The expenditure of these tourists in Spain also grew compared to the previous year (by 18.1\%) to reach 796 million euros. Dividing the total expense by the number of tourists obtains an average expenditure of 1,551 euros per Chinese tourist. After American 
$(€ 2,040)$ and Japanese tourists $(€ 1,802)$, Chinese tourists represent the third nationality for highest expenditure in Spain. According to the data provided by Spain's Secretary of State for Tourism, the main activities carried out by Chinese tourists in 2017 were shopping (74\%), cultural visits $(65 \%)$ and visits to cities (58\%), while only 25\% declared interest in sun and beach activities (Turespaña, 2018). In Spain, the Chinese tourist is defined as a tourist who engages in shopping and cultural consumption (Turespaña, 2018). However, can we be certain that these are the main motivations of today's Chinese tourist? What differences are there between younger and more mature tourists? This article tries to answer these practical questions.

Various authors over recent years have built up a framework of knowledge on Chinese tourism in Spain both through publications of academic articles (Andreu, Claver, \& Quer, 2013; Chen, Guevara, \& Alarcón, 2017; Jericó \& Wu, 2017), doctoral theses and publications derived from them (Lin, 2017; Lojo \& Cànoves, 2015; Peng, 2017) as well as by means of Master's Degree theses (Yue, 2017; Zhu, 2017). Chen et al. (2017) analyzed the image of Spain in the Chinese blogosphere, using the Qyer. com and backpacker.com.tw forums as a source of information. Their analysis has shown a positive image of Spain, and the results highlight that some of the elements that stand out in forming the tourist image are certain cities (Madrid, Barcelona and Granada), soccer and heritage. Jericó and Wu (2017) have analyzed the case of honeymoon tourism among Chinese travelers, and they describe the characteristics of this type of alternative tourism.

Lojo (2016a) analyzed the case of tour operators and concluded that the cities with the greatest presence among organized tours are Barcelona and Madrid, followed at the second level by Seville, Granada and Toledo. Lin (2017) conducted a study of the gastronomic preferences of Chinese tourists in Spain. The author suggests that Chinese cultural values and their previous consumption habits affect their gastronomic experience. Depending on their previous exposure to international food, Chinese tourists in Spain tend to consume Chinese food, local food or international food such as McDonald's. Yue (2017) analyzed the possibilities of the Costa Brava region. The author noted that new Chinese tourist is interested in unspoiled nature and local culture. Zhu (2017) also studied the case of the Costa Brava and highlighted the possibilities of the region's gastronomic and wine tourism.

Since Spain was approved as a tourist destination by the Chinese administration in 2004, the number and profile of tourists have changed. Currently, the main differences among Chinese consumers are between (a) younger / independent tourists and (b) more mature / group tour tourists - with the former having new patterns of consumption and the latter constituting traditional travelers seeking comfort (Lin, 2017). Adding to previous research, Lojo and Li (2018) analyzed the case of Spain and offered a segmentation based on mode of travel and previous travel experience; but they did not take into account the case of younger Chinese tourists.

\subsection{Chinese young tourists}

Research into Chinese young tourists in non-European context show that they are equally or more technologically savvy than Westerners, but still embrace some elements of Chinese culture and tradition (Keith \& Simmers, 2013). Their culture is characterized by its collectivist nature, the importance of the social group, sharing information, reliance upon social monitoring and the giving of small gifts (Blake et al., 2017). In addition, young consumers have recently begun to see international travel as a way to achieve individuality and seek unique experiences. Chinese young tourists prefer individual and self-controlled experiences, which cannot be obtained with a fully organized group package. Distinct from the Western youth, they usually do not enjoy bars, pubs and discos (King \& Gardiner, 2015). 
He and Wei (2014) performed a study of Generation Y travel purchase decisions in the context of China and concluded that there exists a particular consumption behavior that is not well understood by international marketers:

Chinese Gen $Y$ show the strong interest on the natural scenery (beaches for swimming and sunbathing, visiting the countryside), cultural related activities [...], and shopping for brand product such as watches and cosmetics [sic] (He \& Wei, 2014, p. 37).

There has been a change in the profile and tourism behavior of Chinese tourists. However, there are no systematic studies that delve into the experience of young Chinese tourists in Europe; and a lack of empirical research and established frameworks impedes any comprehensive understanding of the differences between younger and more mature tourists. Following the previous considerations, the present study tries to shed light on some comparisons between young and more mature Chinese tourists in Europe, specifically in the case of Spain as a destination.

\section{Case study methodology}

In this study, the tourist's age is used as a variable that allows an a priori differentiation (Dolnicar, 2004) for understanding the differences in the motivations, expectations and satisfaction of Chinese tourists. An a priori differentiation uses segmentation bases that are considered important in the previous academic literature to reach a greater understanding of the tourist's behavior.

This study collects data from a survey-questionnaire administered to Chinese tourists who have traveled to Spain in the last three years. The instrument used is a questionnaire that was distributed as an online survey. The nature of the questions pertains to: (1) the socio-demographic identification; (2) recognition of travel arrangements; and (3) a score indicating their level of agreement (using a fivepoint Likert scale) about a series of items regarding their motivations, expectations and satisfaction. The items used were adapted from previous academic literature (Kim, Guo, \& Agrusa, 2005; Lee, Jeon, \& Kim, 2011; Zhang \& Peng, 2014). The survey and all contact with the sample of Chinese tourists were in the Chinese language. The survey was designed in English and translated into Chinese by a Chinese-Spanish translator. The validity and reliability of the survey was tested through a pilot study at the Barcelona Airport in March 2016. Through the suggestions, opinions and responses of 30 tourists, minor modifications were made.

The survey's target population was Chinese tourists who had traveled to Spain between the years 2014 and 2017. Travelers who went to Spain only for studies or business and did not conduct tourism-leisure activities were not considered. Communication with the respondents occurred through the WeChat online platform. WeChat is the most used messaging and social network service in China, with more than 500 million active users in China (Long, 2017). 80\% of the Chinese population with internet access use this application (China Daily, 2017). Communication with the respondents was carried out using a snowball methodology (Hoogerndoorn \& Back, 2019). This methodology has the advantage of making it possible to get in touch with a large number of respondents without depending exclusively on the researchers' contacts (cf. Lu, Hung, Wang, Schuett, \& Hu, 2016). Snowball sampling has been used frequently to study Chinese tourists (Hsu \& Song, 2013), who are usually elusive. In the first stage, 45 Chinese tourists were contacted directly and were asked to share the survey with contacts in their social network. In the aggregate, 600 responses were received, of which 437 were complete.

We followed the reliability model developed by Chang and Vowles (2013). Thus, we carried out a three-step verification to ensure the reliability of the collected responses: (a) the questionnaire included 
questions of initial screening; (b) the IP addresses of the respondents were verified in order to eliminate questionnaires from the same address; and (c) questionnaires with excessive equal or unanswered responses were eliminated. As a result, 360 surveys were considered acceptable and usable.

Using the SPSS software, the data was analyzed following several protocols. The next section, Case study findings, summarizes the most important results of this case study. First, the descriptive parameters of the sample were obtained (Table 1, Table 2). Second, a mean analysis of the answers was conducted in order to understand the importance given to the items by the whole sample of Chinese tourists (Table 3). Third, a multivariate analysis of variance (MANOVA) series was used to check if there existed significant differences based on the age of respondents. In this way, the age of the respondents is used as an independent categorical variable to show differences in motivations, expectations and satisfaction of tourists (Table 4). The Discussion section interprets the findings, explore the research implications, and connects the results with the current literature. As a result, the discussion offers an overview of the new trends in Chinese travel to Europe.

\section{Findings}

Table 1 shows that slightly more than $50 \%$ of the responders are between 18 to 29 years old, with a somewhat higher proportion of women than men. The vast majority of tourists come from second- or third-tier cities, showing that the tourists in our sample are not restricted to the richest and largest Chinese megalopolises (Table 1).

Table 1

Demographic characteristics

\begin{tabular}{l|l|c|c}
\hline \multicolumn{2}{l|}{ Item } & $\begin{array}{r}\text { Number } \\
(\mathbf{N}=360)\end{array}$ & $\begin{array}{c}\text { Percentage } \\
(\%)\end{array}$ \\
\hline \multirow{3}{*}{ Gender } & Female & 213 & 59.2 \\
& Male & 147 & 40.8 \\
\hline \multirow{5}{*}{ Age } & $18-29$ & 208 & 57.8 \\
& $30-39$ & 70 & 19.4 \\
& $40-49$ & 30 & 8.3 \\
& $50-59$ & 31 & 8.6 \\
& 60 or older & 21 & 5.8 \\
\hline \multirow{5}{*}{ Place of origin } & Beijing & 33 & 9.2 \\
& Shanghai & 88 & 24.4 \\
& Guangdong & 13 & 3.6 \\
& Other Mainland China cities & 222 & 63.5 \\
& Undisclosed & 1 & 0.3 \\
\hline
\end{tabular}

In our sample of respondents, close to $70 \%$ of tourists already had previous travel experiences in other European countries before traveling to Spain. This means that Spain is not usually the first country in Europe that the Chinese tourist chooses to visit (Table 2). 67\% of respondents made their first trip to Spain, but about 30\% were re-visiting this destination. This interestingly indicates that, when they are satisfied with the trip, a notable number of Chinese tourists repeat traveling to the same European country. 
Table 2

Travel experience

\begin{tabular}{l|l|r|r}
\hline \multicolumn{2}{l|}{ Item } & $\begin{array}{r}\text { Number } \\
(\mathbf{N = 3 6 0 )}\end{array}$ & $\begin{array}{c}\text { Percentage } \\
(\%)\end{array}$ \\
\hline \multirow{4}{*}{$\begin{array}{l}\text { No. of times } \\
\text { in Europe }\end{array}$} & First & 113 & 31.4 \\
& Second & 73 & 20.3 \\
& Third or more & 171 & 47.5 \\
& Undisclosed & 3 & 0.8 \\
\hline \multirow{4}{*}{$\begin{array}{l}\text { No. of times } \\
\text { in Spain }\end{array}$} & First & 244 & 67.8 \\
& Second & 41 & 11.4 \\
\hline Travel & Third or more & 69 & 19.2 \\
arrangements & Undisclosed & 6 & 1.7 \\
\hline Want to & Free independent travel & 277 & 76.9 \\
recommend Spain & Organized group - travel agency & 83 & 23.1 \\
\hline Want to & No and not sure & 308 & 85.6 \\
visit Spain again & Yes & 52 & 14.4 \\
\hline
\end{tabular}

\subsection{Motivation, expectations and satisfaction levels}

Regarding their motivations, the results of the surveys first show that tourists are more interested in visiting new settings as well as in resting and relaxing (Table 3). Secondly, the tourists reveal the greater importance they give to increasing knowledge and getting to know Western culture. As regards the expectations of these tourists when visiting Spain, the most attractive attributes are the architecture and the monumental heritage of Spain. They rank in second place the Spanish beaches and sunny weather, followed by ideal climate and clean environment, and culture, sports and lifestyle. Finally, tourists also indicated that they are attracted by the green and natural spaces and the possibility of traveling with friends.

Table 3

Motivations, expectations and satisfaction

\begin{tabular}{l|c|c}
\hline Item (ordered from highly rated to lowly rated) & $\begin{array}{c}\text { Mean } \\
\text { score }\end{array}$ & $\begin{array}{c}\text { Std. } \\
\text { deviation }\end{array}$ \\
\hline With this travel I wanted to... & & \\
- visit new places and settings & 4.58 & 0.67 \\
- rest and relax & 4.51 & 0.65 \\
- increase my knowledge and experience & 4.40 & 0.73 \\
- experience Western Culture & 4.32 & 0.71 \\
- socialize while traveling & 3.60 & 0.99 \\
- go shopping & 3.48 & 0.94 \\
- acquire prestige and status & 3.12 & 1.06 \\
- visit friends and relatives & 3.06 & 1.18 \\
\hline In Spain I expected to experience... & & \\
- Spanish architecture and heritage & 4.26 & 0.72 \\
- beautiful beaches and sun & 4.12 & 0.81 \\
- an ideal climate and clean environment & 4.08 & 0.77 \\
- Spanish culture, sports and lifestyle & 3.96 & 0.81 \\
- natural and green spaces & 3.93 & 0.74 \\
- a place suitable to travel with friends & 3.82 & 0.90 \\
- a peaceful and safe place & 3.45 & 0.94 \\
- shopping facilities & 3.38 & 0.94 \\
\hline
\end{tabular}




\begin{tabular}{l|c|c}
\hline Item (ordered from highly rated to lowly rated) & $\begin{array}{c}\text { Mean } \\
\text { score }\end{array}$ & $\begin{array}{c}\text { Std. } \\
\text { deviation }\end{array}$ \\
\hline I was satisfied with Spanish... & & \\
- beautiful sceneries & 4.48 & 0.61 \\
- historical and cultural legacy & 4.40 & 0.65 \\
- relaxed trip & 4.11 & 0.74 \\
- comfortable trip & 3.97 & 0.80 \\
- affordable price & 3.97 & 0.75 \\
- accommodation services & 3.90 & 0.70 \\
- accessible tourism information & 3.83 & 0.74 \\
- shopping services & 3.70 & 0.77 \\
- services in Chinese language & 3.37 & 0.92 \\
\hline
\end{tabular}

In terms of satisfaction with the trip, the results highlight that Spain is highly appreciated in regard to its settings, landscapes, and cultural heritage (Table 3). Respondents indicate that they are mostly satisfied with relaxation, comfort and competitive prices. The lowest grades have been given to items regarding accommodation, accessible tourist information, shopping services, and services and information in Chinese language.

\subsection{Comparison of young and older tourists}

The MANOVA analysis has shown differences between young tourists (18-29 years) and older cohorts of tourists. First, younger tourists show a significant preference for independent travel. Even though they have similar previous travel experiences within Europe and Spain (Table 4), 92\% of the younger tourists in our sample traveled independently. In contrast, half of the older tourists traveled independently while the other half had opted for a group package. Also, young tourists are more prone to recommending the destination and spreading it positively by word of mouth. The detailed comparison shown in Table 4 points out that significant differences between both groups appear in six motivational items, two expectation items and three satisfaction items.

Young and independent tourists are more motivated by rest and relaxation, increasing knowledge and gaining experiences. They are also more motivated by the socializing aspects of the trip as well as by shopping and by using their travel as a way to stand out and differentiate themselves. Regarding the expectations related to Spain's attributes, younger tourists are different from their older counterparts in that they rank first the "beaches and sun", followed by "Spanish architecture and material heritage", then "the ideal climate and environment". Significantly higher values are given to the sand, sun and beach tourism as well as to the ability to travel with friends while at the destination. In general, younger tourists give higher satisfaction scores to most of the items, and they are more satisfied with the destination. They are significantly more satisfied with the sceneries, the relaxation, and the tourism information. Both young and older tourists are very critical in the satisfaction score they give to services in the Chinese language at the destination.

Table 4

Differences between younger and older tourists

\begin{tabular}{|c|c|c|c|}
\hline \multicolumn{2}{|l|}{ Items } & $\begin{array}{c}18-29 \\
(N=208)\end{array}$ & $\begin{array}{c}30 \text { or older } \\
(\mathrm{N}=152)\end{array}$ \\
\hline \multirow{5}{*}{ Arrangements } & - Travel mode (1: independent; 2: group package) & $1.08^{* *}$ & 1.47 \\
\hline & - Times in Europe (1: first, 2: second; 3: third or more) & 2.21 & 2.11 \\
\hline & - Trips to Spain (1: first, 2: second; 3: third or more) & 1.61 & 1.50 \\
\hline & - Will recommend Spain & $4.44^{*}$ & 4.19 \\
\hline & - Will visit Spain again & 4.43 & 4.24 \\
\hline
\end{tabular}




\begin{tabular}{|c|c|c|c|}
\hline \multicolumn{2}{|l|}{ Items } & $\begin{array}{c}\begin{array}{c}18-29 \\
(\mathrm{~N}=208)\end{array} \\
4.65\end{array}$ & $\begin{array}{c}\begin{array}{c}30 \text { or older } \\
(\mathrm{N}=152)\end{array} \\
4.53\end{array}$ \\
\hline Motivations & $\begin{array}{l}\text { - Visit new places and settings } \\
\text { - Rest and relaxation } \\
\text { - Increase my knowledge and experience } \\
\text { - Experience Western culture } \\
\text { - Socialize while traveling } \\
\text { - Shopping } \\
\text { - Acquire prestige and status } \\
\text { - Visit friends and relatives }\end{array}$ & $\begin{array}{l}4.65 \\
4.64^{* *} \\
4.59^{* *} \\
4.45^{*} \\
3.82^{* *} \\
3.65^{* *} \\
3.32^{* *} \\
3.24\end{array}$ & $\begin{array}{l}4.53 \\
4.43 \\
4.21 \\
4.25 \\
3.43 \\
3.32 \\
2.92 \\
3.23\end{array}$ \\
\hline Expectations & $\begin{array}{l}\text { - Beautiful beaches and sun } \\
\text { - Spanish architecture and material heritage } \\
\text { - Ideal climate and clean environment } \\
\text { - Spanish culture and lifestyle } \\
\text { - Natural and green spaces } \\
\text { - Suitable for traveling with family and friends } \\
\text { - Peaceful and safe place } \\
\text { - Shopping facilities }\end{array}$ & $\begin{array}{l}4.30^{* *} \\
4.26 \\
4.15 \\
3.96 \\
3.96 \\
3.95^{*} \\
3.49 \\
3.49\end{array}$ & $\begin{array}{l}.89 \\
4.32 \\
3.98 \\
3.97 \\
3.95 \\
3.76 \\
3.49 \\
3.36\end{array}$ \\
\hline Satisfaction & $\begin{array}{l}\text { - Beautiful sceneries } \\
\text { - Historical and cultural legacy } \\
\text { - Relaxed destination } \\
\text { - Good price } \\
\text { - Comfortable destination } \\
\text { - Accommodation services } \\
\text { - Accessible tourism information } \\
\text { - Shopping services } \\
\text { - Services in Chinese language }\end{array}$ & $\begin{array}{l}4.55^{*} \\
4.41 \\
4.24^{* *} \\
4.09 \\
4.05 \\
4.02 \\
3.99^{* *} \\
3.73 \\
3.35\end{array}$ & $\begin{array}{l}4.39 \\
4.42 \\
4.00 \\
3.91 \\
3.87 \\
3.86 \\
3.73 \\
3.69 \\
3.40\end{array}$ \\
\hline
\end{tabular}

Note: ${ }^{*}=0.01<p \leq 0.05 ; * * 0.01$

\section{Discussion}

Previous research in other contexts indicates the existence of an evolution in behavior patterns among Chinese outbound tourists (Arlt \& Burns, 2013; Kapiki, Fu, \& Mou, 2015). At the beginning of the 2010s, the Chinese tourist in Europe behaved like a "traditional" Asian tourist: Most of them chose to travel in organized groups and stay in a "comfort bubble". The traditional group tour traveler restricted social interactions at the destination to other Chinese travelers and their group guide. The itinerary and trip activities were chosen beforehand by the travel agency. Within this "bubble", the tourist was protected from unexpected surprises and cultural differences.

Nowadays, Chinese tourists more greatly appreciate interacting with the local culture as they demand experiences while traveling, and they place more value on individuality (Arlt \& Burns, 2013). It has also appeared a new form of family tourism linked to a middle-aged economic elite that has ample purchasing power, which allows they and their children to take trips and demand more exclusive experiences (Bao, Jin, \& Weaver, 2018). In addition, the cruise industry is also starting to come into reach to Chinese tourism (Moundou \& Taunay, 2012). Consistently, the results of this study also show that different tourism patterns currently coexist among Chinese tourists. In our sample, younger tourists prefer independent travel. These tourists do not need to remain within a Chinese group, nor do they wish to be subordinated by a guide, or organized trips. However, an important percentage of older tourists still prefer a fully organized group package. Recent studies show that currently there is demand for different travel arrangements - traditional organized tour, customised tour product, independent travel— which implies different experiences and tourism products consumed (CTA, 2019). 
Firstly, tourists who travel with an organized group to Europe embark on a trip that lasts between 10 and 12 days, and they usually prefer to visit different cities in one or more countries. Tourist itineraries are realized by bus, high speed train or plane (Lojo, 2016a). Secondly, younger and independent tourists show more variability in their travel dynamics. More specifically, they may possibly be: (1) traveling from mainland China; or (2) visiting other European cities while working or studying in Europe. In the first case, the tourists take more time planning the trip, can stay in Europe 12 or more days, spend more time in a single destination, and follow the Chinese holiday calendar (Skift, 2013). In the second case, shorter trips are taken, and usually on weekends or on dates that coincide with the holiday periods of European countries. In addition to the two previously identified travel arrangements, the fully customized private tour, for 3 or 4 people, is increasing in popularity among affluent Chinese tourists. According to the China Tourism Academy, in H1 2019 the customized private tour accounted for only $5 \%$ of the total number of Chinese travelers to Europe, but it has grown by $120 \%$ since the previous year (CTA, 2019).

In this study, $31 \%$ of the visitors across all respondents had never been to Europe prior to this journey. This result is similar to the results of the Copenhagen Tourist Office's survey of Chinese tourists (VisitCopenhagen, 2017), which indicated that $37 \%$ of Chinese tourists to Copenhagen were on their first visit to Europe. In our study, $70 \%$ of the travelers were revisiting Europe, but only $30 \%$ were revisiting Spain. This confirms that the Chinese tourist prefers to travel to other European destinations before going to more eccentric European destinations (such as Denmark or Spain). Therefore, France, Italy, Centre Europe countries, and also to the United Kingdom are usually visited in their first trip to Europe.

Since only $10 \%$ of Chinese citizens nowadays have a passport, it is expected that more "inexperienced" tourists will travel to Europe in the near future. In the case of Spain, mature travelers tend to visit the cities that are most important and overcrowded by tourism, such as Barcelona and Madrid (Spain); or in other countries Rome (Italy) and Copenhagen (Denmark) (VisitCopenhagen, 2017); but young visitors also prefer to enjoy time in peripheral destinations such as, in the case of Spain, the coastal area of the Costa Brava in the north of Catalonia (Yue, 2017). Younger Chinese tourists have their own interests that are outside the main routes and based on their own planning stage, which takes much longer than the planning stage for tourists taking group tours (Skift, 2013). This highlights how important it is that marketers promote less-known destinations and distribute the information to the Chinese market, which will appeal to younger tourists that do not want to be in a crowded destination.

According to our results, Chinese tourists are still dissatisfied with the lack of services in the Chinese language. Young travelers need to have more information in Chinese and ensure that the staff has proficiency in their language. It should be taken into account that to offer more tourism information to ease the planning stage of the trip would be of great benefit to position European destinations. The young Chinese is looking for practical knowledge (how to choose and book accommodation, how to move within the destination, etc.) before they select the destination for their next travel (Lojo \& Timothy, 2020).

This study shows that Chinese tourists in Europe are mainly motivated to visit new places and cultures, seek relaxation, and get to know different cultures. In the case of Spain, the most valued attributes of the destination are: the local historical and monumental heritage; beaches and weather; and sports and local culture. The findings for Spain are similar to those for Greece, where the Chinese tourists value natural spaces, islands and beaches, and Greek culture (Skivalou \& Filippidi, 2017). However, in the case of Spain, our results suggest that natural spaces and nature-based activities are not as well known by tourists. Therefore, more marketing strategies taking into account these natural attractions in Spain are needed. 
This work has shown that the more mature tourist is less motivated by socializing and shopping, and is more interested in cultural trips related to historical and monumental heritage. Younger tourists are more interested in new experiences, sun and beaches, relaxation, leisure and shopping. As for purchases, it is recommended to keep in mind that this type of tourist is very sensitive to price and competitiveness (Jiménez Laó, 2016). The motivations of the Chinese tourists are diversifying and are highly varied, thus it is necessary to conduct more studies of market segmentation. Tourists who have more previous experience or high purchasing power prefer to enjoy personalized experiences in the fields of art, nature, spirituality, education or cultural exchange. For example, Zhu (2017) indicates the importance of more specific motivations such as wine tourism.

In this study, the older tourists are less satisfied with the ability to relax in the destination and give lower satisfaction scores on most of the items. This may be explained by their constituting a higher share of group tour travelers. Traditional organized trips run on a very tight schedule, and many monuments and cities are visited in only a few days. The very busy schedules and routes make actually degrade the tourist experience. In addition, competition between travel agencies can in many cases provoke lower quality of service in order to reduce prices. This could explain this study's findings that older tourists had significantly less interest in recommending the destination. These results are consistent with previous studies that have also indicated lower satisfaction on the part of this type of tourist following their trip (Chen, Schuckert, Song, \& Chon, 2016). Due to the aforementioned reasons, recently the Chinese travel agencies are starting to provide customized and smaller group tours to Europe. Low-cost, low-quality, rushed, and mass-produced tour groups are decreasing in top Chinese travel agencies, and there is noticeable shift to smaller and more personalized tours (CTA, 2019).

Figure 1

Coexisting trends among Chinese travelers in Europe

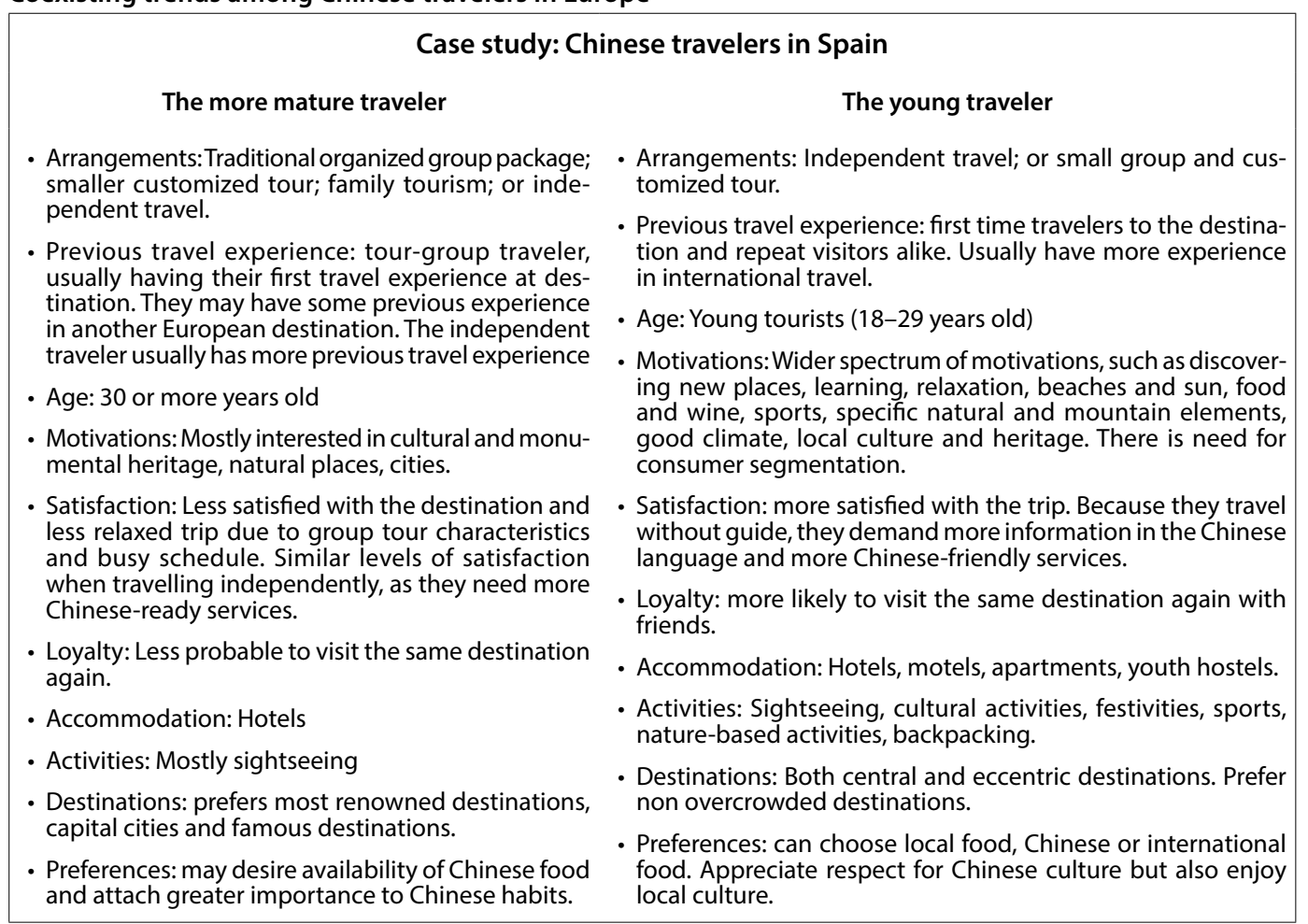


Research shows that older and group-tour tourists usually choose to stay in hotels and they mostly prefer Chinese food while adhering to Chinese schedules and habits. For them, it is wise to adapt the accommodation services to the Chinese consumer with the provision of kettles and hot water; courtesy slippers; and easy access to tourist information (Skivalou \& Filippidi, 2017). In contrast, younger and independent tourists stay in hotels but also in youth hostels and apartments (King \& Gardiner, 2015); and there are students or residents in Europe who can also travel as backpackers (Qian, 2017). These younger tourists show a wider spectrum of interests for travel activities, including sightseeing, local festivities, sports, nature and local food. In accordance with the Findings and Discussion section of this study, Figure 1 shows a summary of the differences among current Chinese tourists in Europe.

\section{Conclusions}

The Chinese tourists of today — and, above all, tomorrow — are young and affluent (Skivalou \& Filippidi, 2017), independent and adventurous (King \& Gardiner, 2015), high-tech and heavy smartphone users (O’ Regan \& Chang, 2015). The Chinese tourist nowadays is very open to the concept of smart tourism and embraces the use of technology while on vacations and takes advantage of new channels of information services. In addition, they are budget conscious and have a high price sensitivity (Dogru, 2016; Pham, Nghiem, \& Dwyer, 2018) and seeks the greatest value for price, whether it be for outbound group packages, customized tours, or independent travel. They need easy access to more practical information ("know-how" knowledge), as well as descriptive information of lesser known destinations ("know-what" knowledge) (Lojo \& Timothy, 2020). The findings of the study show that Chinese travelers in Spain are mostly interested in sightseeing, monumental heritage and the culture of the destination. Younger tourists have a wider spectrum of interests, such as learning, relaxation, sun and beaches, nature-based activities, cultural and local festivities, history, wine and food, and specific elements pertaining to nature, such as the mountains.

In this study we have identified the main fundamental differences in tourism behavior of younger and older Chinese in Europe. The study findings and the discussion will be useful for European marketers and destination management offices (DMO). Specifically, this work is of great value for Spanish DMOs, as it has performed an analysis of the motivations and expectations of Chinese tourists. In addition, satisfaction levels with the destination have been assessed and valuable managerial implications have been discussed. This work shows that there are important differences in the different types of Chinese tourist behavior, and that different trends coexist. Old clichés and stereotypes regarding their behavior are being overcome, and the Chinese tourist wants more than sightseeing and shopping experiences. Research in the context of European destinations is scarce, and more research is needed in order to understand the specific tourist segments of the young Chinese market that are understudied — such as food and wine tourism, sport tourism, nature-based tourism and study tourism (cf. Cheng, Wang, \& Xu, 2013; Kling, 2017; Lin, 2017; Philips \& Brunt, 2013; Yue, 2017, Zhu, 2017). Lastly, another important future research area that will help us grasp future trends in Chinese tourist behavior in Eu-

rope is the evolution of travel arrangements like partially organized group packages, customized tours, semi-independent packages and other in-between modes of travel arrangement.

\section{References}

Agacevic, A., \& Xu (2020). Chinese tourists as a sustainable boost to low seasons in Ex-Yugoslavia destinations. Sustainability, 12(2), 449.

Andreu, R., Claver, E., \& Quer, D. (2013). Chinese outbound tourism: New challenges for European tourism. Enlightening Tourism. A Pathmaking Journal, 3(1), 44-58. 
Andreu, R., Claver, E., \& Quer, D. (2014). Destination attributes and Chinese outbound tourism to Europe. Journal of China Tourism Research, 10(3), 275-291.

Anil, N. K. (2012). Festival visitors' satisfaction and loyalty: An example of small, local, and municipality organized festival. Tourism: An International Interdisciplinary Journal, 60(3), 255-271.

Arlt, W. G., \& Burns, P. (2013). The second wave of Chinese outbound tourism. Tourism Planning \& Development, 10(2), 126-133.

Bao, J., Jin, X., \& Weaver, D. (2018). Profiling the elite middle-age Chinese outbound travellers: a 3rd wave? Current Issues in Tourism, 22(5), 561-574.

Blake, B. F., Neuendorf, K. A., LaRosa, R. J., Luming, Y., Hudzinski, K., \& Hu, Y. (2017). E-Shopping patterns of Chinese and US millennials. Journal of Internet Commerce, 16, 53-79.

Chang, T.-Z., \& Vowles, N. (2013). Strategies for improving data reliability for online surveys: a case study. International Journal of Electronic Commerce Studies, 4(1), 121-130.

Chen, F.-W., Guevara, A., \& Alarcón, P. (2017). Automatically extracting tourism-related opinion from Chinese social media. Current Issues in Tourism, 20(10), 1070-1087.

Chen, Y., Schuckert, M., Song, H., \& Chon, K. (2016). Why can package tours hurt tourists? Evidence from China's tourism demand in Hong Kong. Journal of Travel Research, 55(4), 427-439.

Cheng, M., Wang, L., Xu, X. (2013). The role of ecotourism sites: Transforming Chinese tourists' behavior. Tourism: An International Interdisciplinary Journal, 61(3), 313-316.

China Daily. (2017, January 24). WeChat dominates Chinese mobile app use. China Daily. Retrieved from http://www. chinadaily.com.cn/business/tech/2017-01/24/content_28038940.htm.

CTA (2019) cited in:Travel168 (2019, August 30). Big Data:Chinese tourism to Europe keep growing in H1 2019. Retrieved from http://news.travel168.net/focus_on/20190830/53053.html.

Dolnicar, S. (2004). Beyond "commonsense segmentation": A systematics of segmentation approaches in tourism. Journal of Travel Research, 42(3), 244-250.

Dogru, T. (2016). Chinese propensity to purchase a vacation: The role of financial behavior and confidence in economy. Tourism: An International Interdisciplinary Journal, 64(2), 149-158.

ETC - European Travel Commission. (2019). Chinese tourists flock to Europe. Increase confirms success of EU-China Tourism Year. Report.

Eurostat. (2018). Tourism statistics - EU and China. Retrieved August 12, 2018, from http://ec.europa.eu/eurostat/ statistics-explained/index.php/Tourism_statistics_-_EU_and_China.

He, Y., \& Wei, L. (2014). The relationship of Chinese generation Y's intercultural sensitivity and travel purchase decisions in international leisure travel. In G20 first east-west dialogue on tourism and the Chinese dream (p. 35).

Hoogendoorn, G., \& Back, A. (2019). Snowballing in 35oC: an inquiry into second-home tourism in Mozambique. Tourism: An International Interdisciplinary Journal, 67(3), 311-317.

Hsu, C. H. C., \& Huang, S. (2016). Reconfiguring Chinese cultural values and their tourism implications. Tourism Management, 54, 230-242.

Hsu, C. H. C., \& Song, H. (2013). Destination image in travel magazines A textual and pictorial analysis of Hong Kong and Macau. Journal of Vacation Marketing, 19(3), 253-268.

Jericó, C. A., \& Wu, M. (2017). Características del turismo de luna de miel: aproximación al turismo chino. Cuadernos de Turismo, (40), 65-92.

Jimenez Lao, T. (2016). El auge del turismo chino en España: estudio del certifi cado de calidad Chinese Friendly en la ciudad de Sevilla (Master's thesis). Universidad de Sevilla

Jin, X., \& Wang, Y. (2016). Chinese Outbound tourism research: A review. Journal of Travel Research, 55(4), 440-453.

Jørgensen, M. T., Law, R., \& King, B. E. (2016). Understanding the past, anticipating the future? a critical assessment of China outbound tourism research. Journal of Travel and Tourism Marketing, 34(7), 880-891.

Jørgensen, M. T., Law, R., \& King, B. E. (2018). Beyond the stereotypes: Opportunities in China inbound tourism for second-tier European destinations. International Journal of Tourism Research, 20(4), 488-497. 
Kapiki, S. T., Fu, J., \& Mou, L. (2015). Strategic framework showcasing Greece in the Chinese tourism market. Euromed Journal of Business, 10(3), 311-326.

Keith, N. K., \& Simmers, C. S. (2013). Adapting the marketing educational environment for multi-cultural millennials: the Chinese experience. Academy of Educational Leadership Journal, 17(3), 83-92.

Kim, S. S., Guo, Y., \& Agrusa, J. (2005). Preference and positioning analyses of overseas destinations by Mainland Chinese outbound pleasure tourists. Journal of Travel Research, 44(2), 212-220.

King, B., \& Gardiner, S. (2015). Chinese international students. An avant-garde of independent travellers? International Journal of Tourism Research, 17(2), 130-139.

Kling, K. G. (2017). Trails for tourism and outdoor recreation: A systematic literature review. Tourism: An International Interdisciplinary Journal, 65(4), 488-508.

Lee, S., Jeon, S., \& Kim, D. (2011). The impact of tour quality and tourist satisfaction on tourist loyalty: The case of Chinese tourists in Korea. Tourism Management, 32(5), 1115-1124.

Lin, J. (2017). Food consumption of Chinese outbound tourists in Spain (Doctoral dissertation). Universitat de Girona.

Lojo, A. (2016a). Chinese tourism in Spain: An analysis of the tourism product, attractions and itineraries offered by Chinese travel agencies. Cuadernos de Turismo, (37), 243-268.

Lojo, A. (2016b). Turismo Chino emisor: Estado de la cuestión y agenda. Boletín de La Asociación de Geógrafos Españoles, (72), 471-500.

Lojo, A., \& Cànoves, G. (2015). El turismo chino en Barcelona. Elementos clave de un fenómeno reciente. Documents d'Anàlisi Geogràfica, 61(3), 581-599.

Lojo, A., \& Li, M. (2018). Segmentation by experiential familiarity and travel mode of the Chinese outbound market to Spain. Journal of China Tourism Research, 14(1), 100-121.

Lojo, A., Li, M., \& Cànoves, G. (2019). Co-authorship networks and thematic development in Chinese outbound tourism research. Journal of China Tourism Research, 15(3), 283-294.

Lojo, A., \& Timothy, D. J. (2020). Understanding tourism information sources: textual communication, efficiency and information gaps. Tourism Analysis, 25(1), 91-105.

Long, D. (2017, July 12). WeChat users in China to reach nearly 500 million in 2017. The Drum.

Lu, J., Hung, K., Wang, L., Schuett, M. A., \& Hu, L. (2016). Do perceptions of time affect outbound-travel motivations and intention? An investigation among Chinese seniors. Tourism Management, 53, 1-12.

Maumbe, K., \& Arbogast, D. (2015). Relationship between visitor motivations, destination evaluation and future behavior intentions: The case of West Virginia. Tourism: An International Interdisciplinary Journal, 63(4), 465-478.

Moundou, V., \& Taunay, B. (2012). The adaptation strategies of the cruise lines to the Chinese tourists. Tourism: An International Interdisciplinary Journal, 60(1), 43-54.

O'Regan, M., \& Chang, H. (2015). Smartphone adoption amongst Chinese youth during leisure-based tourism: Challenges and opportunities. Journal of China Tourism Research, 11(3), 238-254.

Peng, X. (2017). Evolución e internacionalización del turismo chino: situación actual y posibilidades españolas (Doctoral dissertation). Universidad de Alicante.

People's Daily (2019). 3 mln Chinese tourists visit Europe in first half of 2019. People's Daily Online. Retrieved from http://en.people.cn/n3/2019/0822/c90000-9608224.html

Pham, T. D., Nghiem, S., \& Dwyer, L. (2018). The economic impacts of a changing visa fee for Chinese tourists to Australia. Tourism Economics, 24(1), 109-126.

Philips, J., \& Brunt, P. (2013). Tourist differentiation: Developing a typology for the winter sports market. Tourism: An International Interdisciplinary Journal, 61(3), 219-243.

Qian, W. (2017). SWOT analysis and related countermeasures for Croatia to explore the Chinese tourist source market. Croatian International Relations Review, 23(78), 169-185.

Rodriguez-Guiron, S. (2018). Determinants for tourist destinations' international markets access: The case of Southern Ecuador and Germany. Tourism: An International Interdisciplinary Journal, 66(3), 282-301. 
Skift. (2013). Rise of the Chinese independent traveler. New York.

Skivalou, M., \& Filippidi, E. (2017). Chinese tourism: Development and prospects for Greece. Tourism and Hospitality Research, 17(3), 325-335.

Smallman, C., \& Moore, K. (2010). Process studies of tourists' decision-making. Annals of Tourism Research, 37(2), 397-422.

Travel China Guide. (2018). 2017 China tourism facts and figures. Retrieved June 14, 2018, from https://www.travelchinaguide.com/tourism/2017statistics/

Turespaña. (2019). Ficha ejecutiva —China. Marzo 2019. Madrid.

VisitCopenhagen. (2017). Chinese tourists are all kind of travellers. 2016 survey of Chinese tourists in nordic cities. Copenhagen.

Xinhua (2019). Chinese tourists make nearly 150 million outbound trips in 2018. Retrieved from http://www.xinhuanet. com/english/2019-02/13/c_137818975.htm

Yue, D. (2017). La nueva tendencia del turismo chino: Una propuesta para viajeras chinas basado en los recursos culturales de Costa Brava (Master's thesis). Universitat de Girona.

Zhang, Y., \& Peng, Y. (2014). Understanding travel motivations of Chinese tourists visiting Cairns, Australia. Journal of Hospitality and Tourism Management, 21, 44-53.

Zhu, D. (2017). El enoturismo para el mercado chino. Propuesta de promoción de la Costa Brava (Master's thesis). Universitat de Girona.

Received: 09/01/2019

Accepted: 23/01/2020 